\title{
Construction on Process Teaching Evaluation Index System for Rotational Classroom
}

\author{
Jun Yang ${ }^{1, a}$, Yuyang $\mathrm{Zu}^{2, b}$ \\ ${ }^{1}$ School of Education and Sports, Bohai University, Jinzhou, 121013, China \\ ${ }^{2}$ College of Foreign Languages, Bohai University, Jinzhou, 121013, China \\ ayj690213@126.com, b1143119122@qq.com
}

\begin{abstract}
Keywords: rotational classroom; process evaluation; teaching evaluation; index system; construction principle; teaching process
\end{abstract}

\begin{abstract}
In this paper, from the perspective of procedural evaluation index system, will turn the classroom teaching idea and process of teaching evaluation, the combination of complement and development of the process of teaching evaluation in turn the classroom teaching practice, the application of preliminary discussion from a new Angle rotation of classroom teaching evaluation system in our country. This paper not only studied the theory, has collected a large number of colleges and universities teaching evaluation at home and abroad experience and relevant data such as undergraduate teaching evaluation theory research results, combine theory with practice, formulated the procedural teaching evaluation system of scale, and use the tell the research method of combining qualitative analysis and quantity analysis to create rotation process of classroom teaching evaluation system.
\end{abstract}

\section{Introduction}

The establishment of evaluation index system is very difficult, each of these indicators to ensure the impartiality and fairness, independence and integrity of the need to do is quite complicated procedures. In building process, the evaluation standards of every index from practice, the teachers, it as the evaluation standard is more able to meet the needs of teachers, is easy to be transformed into the standard teacher practice. However, this pure form by individual teachers are under the influence of the teachers themselves, but it is difficult to get enough valid samples, at the same time, considering the effective teaching behavior in classroom teaching teacher description may be difficult and deviation.

In the process of this research, deductive methods of traditional theory was used to construct conforms to turn the classroom teaching evaluation index system, and through practical test, for the construction of the index system of ongoing cuts, adjustment and optimization, and adjusted the evaluation index system of classroom teaching reflection. Namely, through the analysis of the basic elements of classroom teaching on the basis of the formation of level 1, 2 tertiary indicators, completing the process of turning the classroom teaching evaluation index system of building. This method is easy to form a can reflect the characteristics of the rotation of classroom teaching, guiding, scientific and comprehensive evaluation system, can effectively for the teaching design, teachers before class and after class teaching reflection, can better play to the readjustment of the evaluation, the orientation of function

\section{General Teaching Process on Rotational Classroom}

Rotational classroom generally includes three processes:

(1) The preparation before class. Teachers need to according to the syllabus three-dimensional analysis clear teaching goal. In this way can teaching targeted and integrity, specific teaching method. Before turning the classroom teaching mode implementation, the need for a clear teaching target analysis, such as what need research-style teaching mode and what need to direct teaching and so on. It has a clear teaching goal can facilitate the selection of video, optimizing the teaching 
process, in order to achieve the best teaching effect. Turn the classroom, students are usually released by watching the teacher teaching video to complete the internalization of knowledge and obtain before class. In today's network resources are very abundant, the teaching video quality is good and bad are intermingled, how to better gathering, editing, video is the key of the flip of classroom teaching. It should be based on students' personality and demand and the teaching goal, to complete video editing. Edited video can be shared by teachers through the school website, QQ group, DVD burn tool such as complete release, for students to master learning.

(2) Students knowledge internalization. Students according to their own actual situation through the teacher released video of autonomous learning, and it can avoid the waste of class time, to a certain extent. Students in the process of watching video, meet don't understand the place can take notes, so students can master the pace of learning. After the students can according to your own notes to arrange and internalization of knowledge, draw the knowledge points in the video frames and list has yet to master the content of the convenient communication and asking questions in class. Second, students need to complete specific assigned by the teacher after watching a video classroom practice. According to the theory of the zone of proximal development ", the teacher need to video, to the difficulty of the teaching goal, complete design reasonable test before class, guides the student to complete the fusion of old and new knowledge, more in-depth understanding of the knowledge in class. In addition, teachers should also through QQ, blogs, teaching platform tools such as encountered in the understanding of students learning process doubts, on understanding of the students the actual situation at any time, do prepared for class of solutions.

(3) The classroom teaching. Due to their knowledge structure, ability to accept and perspective there are different degrees of difference, the difference will make students produce cognitive imbalance, the difference of new cognitive structure. Therefore, in the process of classroom teaching activities, teachers should do sufficient preparation, practice for students to solve in the video and the problems in the process. Students can also be used in the class activities, and put forward own confusion, and share communication between teachers and students, to achieve resource sharing, the purpose of learning knowledge. Second, the classroom teaching, the teacher not only need to reassure preaching, also need to provide the classroom practice, lets the student independently scientific experiments. Leave the students in the process of do homework independently, and further complete the construction of knowledge and learning. This is also turn the classroom a great charm. Then, the student from independent inquiry process still need to learn the new knowledge in understanding depth of communication in the team coordination, so as to achieve better absorb knowledge. Under normal circumstances, the students can be divided into several groups, 3-4 as appropriate, students can be personal knowledge with team members to discuss before class, do the sharing of knowledge. At the same time, teachers need to walk down the platform, into the students' cooperative exploration, to give students timely help and the correct guidance. In group work to explore the students' divergent thinking and attitude towards learning will have great change, also reflected the teachers and students "dominant one subject" status. After class exercises, students with an individual or a group representative by report, in the form of speech, competition and sharing. Other students, teachers, to review the report person, its valuable place give affirmation, lack of places to give guide to correct. Students can through this way constantly perfect themselves, enhance self-confidence, and cultivate the ability to solve the problem. Teachers can also through the process, a clear knowledge of master degree students, complete the teaching pertinence, in order to achieve the best teaching effect.

\section{Construction Principle on Evaluation Index System}

Rotational classroom teaching evaluation index system construction should be based on the general principles of the teaching evaluation index system of construction: the overall integrity and objectivity principle, the principle, operational principle, direction and level index mutual independence principle, etc.

(1) The overall integrity and objectivity principle: the overall integrity is evaluation index can contain detailed performance of teachers and students of teaching activities, also need to be able to 
system reflect the individual and the overall evaluation result; The objectivity principle is to use the index of teachers and students of the specific situation to make objective evaluation in the process of teaching. Indicators to fully reflect the overall development of accurate, upper indicators as an important part of shall form a sufficient and necessary relationship between each other, while the lower level indicators to achieve the upper indexes required by the target and requirements.

(2) The directional principle: the direction of the evaluation is the goal of education is becoming more refinement, it makes teaching more concrete, more targeted, it is in view of the education a set standard in a certain direction. When making the evaluation index, therefore, to combine the teaching purpose and to cut the actual investigation, the purpose of education can't deviate from teaching.

(3) The feasibility principle: the evaluation of system behavior as evaluation objects and embodies a kind of objective basis, should have easy operation, wide range of conditions, such as about its description should reflect its maneuverability, users can easily be understood, and the ability to do practical role in guiding, observation of the evaluation results also to be able to clear and understanding.

(4) With hierarchy index mutual independence principle: cannot exist interdependence between same level indicators, each indicator should be isolated, should not have been able to generate the index structure chain effect, a measure that could not serve as the cause of another indicator or as a result, the inclusion relation can't exist, cannot exist interdependence, cross relationship, such as a measure to ensure the independence.

\section{Construction on Evaluation Index System}

Based on the practical application of rotational classroom, this paper constructed by "teaching design, teaching process and teaching effect" of the primary index, index of each class and contains a number of secondary indexes, under the instructions are as follows:

(1) The teaching design, including the "teaching material and teaching content" two secondary indexes. Among them, the teaching material, including two aspects, one is that the courseware material conform to the teaching outline and teaching objectives; The second is, video material suitable length of time, highlight the teaching content. The teaching content, including three aspects: one is that the teaching goal of clarity and concreteness, consistent with students' actual situation and teaching outline; Second, the proposed the key difficulties of correct teaching and seize the key knowledge points; Three is that great importance to the development of teaching resources and integration, can contact the student life and social life.

(2) The teaching process, including "behavior of teachers, teaching methods and student activities, such as three secondary indicators. Among them, the teachers' behavior, including five aspects, one is the teaching with clarity, class structure is rigorous, reasonable density of teaching; Second, strain capacity, organization and coordination ability and strong ability to timely evaluation, at the same time to focus on students, according to the different students according to their aptitude; Three is that teaching language accurately, appropriately, teaching attitude kind, can timely solve students confused; Four is, encouraging students to practice independently, to students think time; Five is to cultivate the students' comprehension ability, make them understand the origin of the knowledge, stimulate creativity. Teaching methods, including four aspects, one is that teaching and training of combination of theory and practice, knowledge after further implement down; Second, avoid rigid teaching methods, combining with the actual situation as well as suitable for students of teaching method, has the characteristics of flexible; Three is that learning before teaching, classroom training; Four is that modern teaching means such as multimedia, teaching AIDS, using proper, efficient service in the teaching work. Student activities, including three aspects: one is that students actively participate in teaching activity, good study habits; Second, individual learning independently, independently complete the team cooperation to explore; Three is to share knowledge actively, puts forward problems and new insights.

(3) Teaching effectiveness, including "the emotional education, teaching education and personality" and other three secondary indicators. Among them, the emotional education, including 
two aspects, one is that the teachers and students have equal status, get along, the classroom atmosphere is good, pay more attention to the cultivation of creativity in class; Second, pay close attention to the students' interests, learning habit and learning motivation, confidence, habits, emotions, such as cultivating non-intellectual factors. Teaching education, including three aspects, one is that the teaching effect is good, the teaching goal; Second, active classroom atmosphere, students actively participate in; Three is professor, knowledge has the appropriate amount of information, pay attention to the formation of the knowledge system, short-term efficient. Teaching personality, including two aspects, one is, has a unique teaching style, to ensure the quality of learning with individual character characteristic; Second, a good relationship between teachers and students, equal status, get along well.

\section{Conclusion}

In this study, the traditional theory of deductive method to construct conforms to turn the classroom teaching evaluation index system, and through practical test, for the construction of the index system of ongoing cuts, adjustment and optimization, and adjusted the evaluation index system of classroom teaching reflection. Namely, through the analysis of the basic elements of classroom teaching on the basis of the formation of level 1, 2 tertiary indicators, completing the process of turning the classroom teaching evaluation index system of building. This method is easy to form a can reflect the characteristics of the rotation of classroom teaching, guiding, scientific and comprehensive evaluation system, can effectively for the teaching design, teachers before class and after class teaching reflection, can better play to the readjustment of the evaluation, the orientation of function.

The purpose of this study is that in the historical dimension (vertical) and the macro sphere of comparative dimension (horizontal) to know the basic problems in turn the classroom, on this basis, through extensive research and in turn the classroom teaching mode and teaching to grasp the overall situation, the analysis of the existing remains to be improved, and put forward effective reform strategy. Will process is used to turn the classroom teaching evaluation, give full play to the characteristics of procedural teaching evaluation and turn the classroom advantage, has strong practical significance. At the same time, from the perspective of procedural evaluation index system, will turn the classroom teaching idea and process of teaching evaluation, combining to make turn the classroom teaching process more accords with the cognitive law of students; Supplement and development of the procedural teaching evaluation in turn the classroom teaching practice, the application of strives to provide the new train of thought to turn the classroom teaching evaluation in China.

\section{Acknowledgement}

This work is supported by Teaching reform project of Bohai university in 2015: Research on evaluation index system construction and action for process teaching of flipped classroom (BDJG-15-YB-B-012); Postgraduate teaching reform project of Bohai university in 2015: Action research on "ability to advanced" under the primary school education professional master talent training mode reform; Research project of undergraduate teaching reform of higher education in Liaoning Province in 2014: Action research on primary school education professional talent training mode reform based on standard.

\section{References}

[1] X. Q. Zhu, H. Zhang, "Evaluation System of College PE Teachers' Professional Quality," Journal of Chengdu Sport University, vol. 40, no. 6, pp. 85-90, 2014.

[2] J. F. Liu, Z. X. Zhong, "Research on project based learning model," Studies In Foreign Education, vol. 39, no. 11, pp. 54-55, 2002. 
[3] H. Zhang, X. J. Wu, "The connotation and theoretical basis of deep learning," China Educational Technology, vol. 33, no. 10, pp. 7-8, 2012.

[4] S. Lan, "Based on KLEE and fuzzy comprehensive evaluation operator cognitive ability assessment," Ergonomics, vol. 16, no. 1, pp. 30-31, 2010.

[5] X. L. Zhong, S. Q. Song, L. Z. Jiao, "Research on instructional design based on flipped classroom concept in information environment," Open Education Research, vol. 19, no. 1, pp. 59-60, 2013.

[6] Roxana Enache, Alina Crisan, "The Analysis of Teachers' Skills and Abilities for the Pre-university System in the Initial and Continuous Training Programs," Procedia - Social and Behavioral Sciences, vol. 114, no. 21, pp. 519-526, 2014.

[7] K. K. He, "The essence of 'flipped classroom' and the future development of 'flipped classroom' in our country," E-education Research, vol. 35, no. 7, 5-16, 2014.

[8] P. Wen, "On the Enlightenment of the 'fourth generation evaluation theory' to the undergraduate teaching evaluation in China," China Adult Education, vol. 19, no. 17, pp. 136-136, 2010.

[9] P. Liu, "The practice and exploration of information evaluation of primary and secondary school education in Pudong New Area of Shanghai city," Educational measurement and evaluation , vol. 3, no. 12, pp. 12-15, 2010.

[10] Marek Cezary Zdun. On set-valued iteration groups generated by commuting functions[J]. Journal of Mathematical Analysis and Applications, 2013, 398(2): 638-648. 